\title{
Extracellular matrix formation after transplantation of human embryonic stem cell-derived cardiomyocytes
}

\author{
L. W. van Laake • E. G. van Donselaar · J. Monshouwer-Kloots • \\ C. Schreurs · R. Passier • B. M. Humbel • P. A. Doevendans · \\ A. Sonnenberg $\cdot$ A. J. Verkleij $\cdot$ Christine L. Mummery
}

Received: 8 August 2009/Revised: 29 September 2009/ Accepted: 7 October 2009/Published online: 22 October 2009

(C) The Author(s) 2009. This article is published with open access at Springerlink.com

\begin{abstract}
Transplantation of human embryonic stem cellderived cardiomyocytes ( $\mathrm{hESC}-\mathrm{CM}$ ) for cardiac regeneration is hampered by the formation of fibrotic tissue around the grafts, preventing electrophysiological coupling. Investigating this process, we found that: (1) beating hESC-CM in vitro are embedded in collagens, laminin and fibronectin, which they bind via appropriate integrins; (2) after transplantation into the mouse heart, hESC-CM continue to secrete collagen IV, XVIII and fibronectin; (3) integrin expression on hESC-CM largely matches the matrix type they encounter or secrete in vivo; (4) co-transplantation of hESC-derived endothelial cells and/or cardiac progenitors with hESC-CM results in the formation of functional capillaries; and (5) transplanted hESC-CM survive and mature in vivo for at least 24 weeks. These results form the basis of future developments aiming to reduce the adverse fibrotic reaction that currently complicates cell-based therapies for
\end{abstract}

Electronic supplementary material The online version of this article (doi:10.1007/s00018-009-0179-z) contains supplementary material, which is available to authorized users.

L. W. van Laake $\cdot$ P. A. Doevendans

Heart Lung Center Utrecht, Utrecht, The Netherlands

E. G. van Donselaar · B. M. Humbel · A. J. Verkleij Cellular Architecture and Dynamics, Faculty of Sciences, Utrecht University, Utrecht, The Netherlands

J. Monshouwer-Kloots · C. Schreurs · R. Passier .

C. L. Mummery $(\bowtie)$

Department of Anatomy and Embryology, Leiden University

Medical Center, Postal zone: S-1-P, P.O. Box 9600,

2300 RC Leiden, The Netherlands

e-mail: c.l.mummery@lumc.nl

A. Sonnenberg

The Netherlands Cancer Institute, Amsterdam, The Netherlands cardiac disease, and to provide an additional clue towards successful engraftment of cardiomyocytes by co-transplanting endothelial cells.

Keywords Stem cells - Extracellular matrix ·

Cell transplantation $\cdot$ Myocardial infarction $\cdot$ Blood vessels

\section{Introduction}

Heart failure is one of the most prevalent causes of morbidity and mortality worldwide and is most commonly due to loss of cardiomyocytes after myocardial infarction (MI) [1]. Until recently, loss of viable cardiomyocytes was considered irreversible since the adult mammalian myocardium lacks the ability to regenerate. However, with the discovery of stem cells with the capacity to differentiate into cardiomyocytes and other cardiac cells, it may be possible to replenish the diseased heart with new myocardium [2,3]. Human embryonic stem cells (hESC) are one source that holds promise in this respect, since they can proliferate indefinitely in culture and differentiate into cardiomyocytes with acceptable efficiencies [4-6], thus providing a potential source of cells for both chronic and acute applications. However, aside from their ethical sensitivity, several scientific issues need to be addressed before clinical application becomes feasible. Questions have emerged from studies on the engraftment of hESC-derived cardiomyocytes (hESC-CM) in uninjured, infarcted, and arrhythmic hearts of experimental animals [5, 7-11]. These issues concern primarily integration, survival, safety, immunogenicity and ability to contribute to long-term contractile function. When hESC-CM were transplanted into electrophysiologically silenced guinea pig and swine hearts, they acted as biological pacemakers for 
the recipient myocardium $[8,11]$. This indicated that donor hESC-CM can couple functionally to host cardiomyocytes, which is a prerequisite for a safe and effective outcome of such cell-based therapies. On the other hand, in studies where histological results were extensively analyzed, grafts consisting of hESC-CM were found to be largely isolated from the host myocardium by extracellular matrix both in infarcted and non-infarcted hearts $[5,7,9,10]$. While extracellular matrix provides a structural, chemical, and mechanical substrate that is essential for development and responses to pathophysiological signals [12], inappropriate or excessive secretion may have adverse effects. It could, for example, lead to separation of donor from host cardiomyocytes. Although this would not necessarily exclude functional coupling completely, since electrophysiological signaling can be conducted through relatively thick layers of fibrotic tissue [13], it could increase the risk of arrhythmias [14] especially in larger animals and humans if a similar fibrotic layer developed. Additionally, impaired coupling of donor and host cells may in part explain why cell transplantation has been more successful in improving short- and mid-term cardiac function after MI than in providing sustained long-term functional improvement $[10,15]$. It would therefore be useful to determine the characteristics and origin of the fibrotic tissue surrounding hESC-CM grafts, so that strategies aimed at reducing matrix deposition could be developed. Encapsulation of the graft can be seen as simply a reaction of the host to exogenous cells, but another possibility is that hESC-derived cells produce their own extracellular matrix to create a more suitable local environment, or niche. It is not thought that the fibrotic layer is merely the result of mouse reaction to human tissue since encapsulation also occurs in transplantations from mouse to mouse [16].

The capacity of cells to attach to and thrive in a particular matrix depends on the expression of integrins, heterodimeric transmembrane receptors composed of $\alpha$ - and $\beta$-subunits, at their cell surface. Individual cells may express multiple integrins, which allow them to interact with multiple extracellular matrix ligands [12]. The integrin expression pattern of hESC-CM is currently unknown, but would be useful for understanding mechanisms available for anchoring in recipient heart tissue and how they modulate their own environment to create an optimal niche for survival and integration. In addition, it may shed light on the selective survival of hESC-CM in the heart compared to other cell types $[9,10]$. In a recent study, we detected a dense fibrotic layer around hESC-CM grafts at the electron-microscopic (EM) level 12 weeks after transplantation [10]. It is presently unknown when fibrosis develops, when it reaches a maximum, and how long grafted cells are under suboptimal conditions. If excessive extracellular matrix formation is a late reaction, graft survival may not significantly exceed 12 weeks, the longest follow-up time reported so far. Alternatively, compensatory mechanisms may develop that support graft survival, for example neovascularization through the fibrotic layer.

Here, we address these questions by analyzing healthy and infarcted mouse hearts at several time-points after intramyocardial transplantation of hESC-CM, with a follow-up to 24 weeks. We determined the composition of the extracellular matrix surrounding the grafts with respect to matrix type and origin. In addition, we characterized the integrin expression of hESC-CM in vitro before transplantation and at various time-points thereafter. We also carried out an extensive EM study using immunogold labeling of GFP to identify the genetically marked human cells and monitor their behavior in the graft over time.

\section{Materials and methods}

Cell culture, differentiation and dissociation

HES3-GFP cells [17] were co-cultured with END2 cells to induce cardiomyocyte differentiation $[6,18]$. Large numbers of beating areas were obtained within 12 days that consisted of $20-25 \%$ cardiomyocytes and $75-80 \%$ endodermal or other mesodermal derivates [6, 19]. Beating areas were dissected and dissociated with collagenase A (Roche, Cat. No. 11088858 001) as previously described $[6,20,21]$. One million cells were taken up in a final volume of $5 \mu \mathrm{l}$ of fresh culture medium (DMEM $+20 \%$ FCS) and used for transplantation. For immunofluorescent staining, beating areas were isolated, fixed and processed for cryosections as described [21] or for electron microscopy (see below).

\section{Animals and surgical procedures}

The investigation conforms to the Guide for the Care and Use of Laboratory Animals published by the US National Institutes of Health (NIH Publication No. 85-23, revised 1996) and in line with the 'Ethical principles and guidelines for scientific experiments on animals' of the Swiss Academy of Medical Sciences, and was approved by the Institute Animal Care Committee. Male NOD-SCID mice (Charles River) of 12 weeks of age were used ( $n=32$; 4-6 per time-point per condition). MI was induced under isoflurane anesthesia by ligation of the left anterior descending coronary artery (LAD) as described [21]. The surgical procedure for non-infarcted mice was identical but without ligation of the LAD. In the same operation, cells were injected in the infarcted or healthy myocardium of the free left ventricular wall using an insulin syringe with 
incorporated 29G needle. At 2 days, and 4, 12, and 24 weeks after surgery, animals were euthanized and the hearts were fixed and processed either for cryosections as described [21] or for electron microscopy (see below).

\section{Human fetal heart tissue}

The investigation conforms to the principles outlined in the Declaration of Helsinki. Human fetal hearts were obtained after elective abortion and with informed consent after approval by the Institutional Ethics Committee.

\section{Immunofluorescence and confocal microscopy}

The entire region containing GFP-expressing cells of each heart was cut into $6-\mu \mathrm{m}$ cryosections, which were stained as described [21, 22] (antibodies and dilutions are in the electronic supplementary material, ESM). Isotype-matched controls were performed for all antibodies.

Confocal laser scanning microscopy (sequential scanning for DAPI and Alexa 405 with excitation laser $405 \mathrm{~nm}$, GFP with $488 \mathrm{~nm}$, Cy3 with $532 \mathrm{~nm}$ and Cy5 with $633 \mathrm{~nm}$ ) was performed on a Leica TCS SPE confocal with DMI4000B microscope using LAS-AF software. Cell ${ }^{\circledR}$ software (Olympus) was used to quantify the amount of matrix, comparing different time-points (note: matrix types cannot be quantified in absolute numbers due to differential affinity of the antibodies). Investigators were blinded for time-point and matrix or integrin type scoring.

\section{Immunogold labeling and electron microscopy}

Hearts were perfusion-and subsequently immersionfixed with $2 \%$ formaldehyde $/ 0.05 \%$ glutaraldehyde in

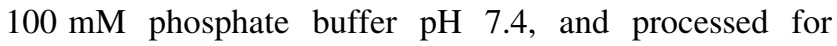
Tokuyasu cryo-sectioning [23, 24]. Colonies of hESCs or beating areas were immersion-fixed with the same fixatives. $60 \mathrm{~nm}$ sections were labeled with antibodies against GFP (1:100) (rabbit; Abcam), cytokeratin 8 (troma-1) (1:3) (rat; Developmental Studies Hybridoma Bank), Tra-1-60 (1:60) (mouse; Chemicon), and human von Willebrand Factor (1:300) (mouse; clone CLB-RAg 38, a kind gift from Prof. P.H. de Groot). Isotype-matched controls were performed for each antibody. Primary antibodies were detected with protein A 10 or $15 \mathrm{~nm}$ gold (Utrecht Medical Center, Cell Microscopy Center) [25], and imaged with a JEOL 1010 electron microscope at $80 \mathrm{kV}$.

\section{Results}

The development of extracellular matrix around hESC-CM grafts over time is summarized in Table 1 and quantified in
ESM Fig. 3. We first determined the matrix proteins present in isolated beating areas of hES3-GFP at the 12-day time-point when transplantation normally took place. Cardiomyocytes in beating areas were surrounded by collagen I, collagen IV, collagen XVIII, total laminin including laminin 1, 8, 10 and other isoforms, and fibronectin (Fig. 1a-e), but laminin-211 was absent. These matrix components are all normally present in the mammalian myocardium, where collagen $\mathrm{I}$ is secreted by fibroblasts, collagen IV by cardiomyocytes, and laminin and fibronectin by both [26]. Collagen XVIII is present in the adult heart only in blood vessels [27], but we found it to be highly expressed throughout the human fetal myocardium until 16 weeks of gestation (ESM Fig. 1). HESC-CM expressed one or more integrins that enabled binding to each matrix type (Fig. 1f-m): $\alpha 11$ for collagen, little $\alpha 3$ and $\alpha 6$ for laminin (in addition $\alpha 7$ was expressed at the RNA level; no antibody was available) (ESM Fig. 2), $\alpha 5$ and $\alpha \mathrm{V}$ for fibronectin and fibronectin/vitronectin, respectively, and integrin $\beta 1$ that can heterodimerize with all of these $\alpha$ subunits.

We then analyzed grafts, identified by GFP-fluorescence as previously [10], 2 days, and 4 and 12 weeks after transplantation in non-infarcted hearts of NOD-SCID mice. From 4 weeks onwards, these grafts consisted almost exclusively of cardiomyocytes due to their preferential survival, as described [10, 28]. At all time-points, collagen I was expressed homogeneously throughout the myocardium and in the scar tissue resulting from the intramyocardial injection (Fig. 2a-b). However, at 4 and 12 weeks, excessive quantities of collagen I encapsulated most of the grafted cells (Fig. 2b). This over-secretion may be host-derived since collagen I is secreted by fibroblasts and not cardiomyocytes, and no human fibroblasts were found in the mouse heart despite an extensive search using EM. Using human-specific antibodies, human collagen IV and human collagen XVIII were identified around hESC-CM at all time-points (Fig. 2c-f). Moreover, at 4 and 12 weeks after transplantation, patches of human collagen IV and XVIII were also present at some distance from the grafts. Thus, hESC-CM secreted substantial amounts of collagen IV and XVIII in vivo in the mouse heart. Laminin also enveloped hESC-CM at all time-points but not excessively (Fig. 2g, h). Laminin-211 was absent in grafts 2 days post-transplantation, but became expressed thereafter in the same moderate quantities as laminin (Fig. 2i, j). Thus, laminins may be donor- and/or hostderived, but do not contribute significantly to the fibrotic tissue separating donor from host cells. Fibronectin filled the graft area abundantly 2 days after transplantation but this decreased over time (Fig. 2k, 1). Human fibronectin was less prevalent by 4 weeks after transplantation, while mouse fibronectin was reduced by 12 weeks. Taken 


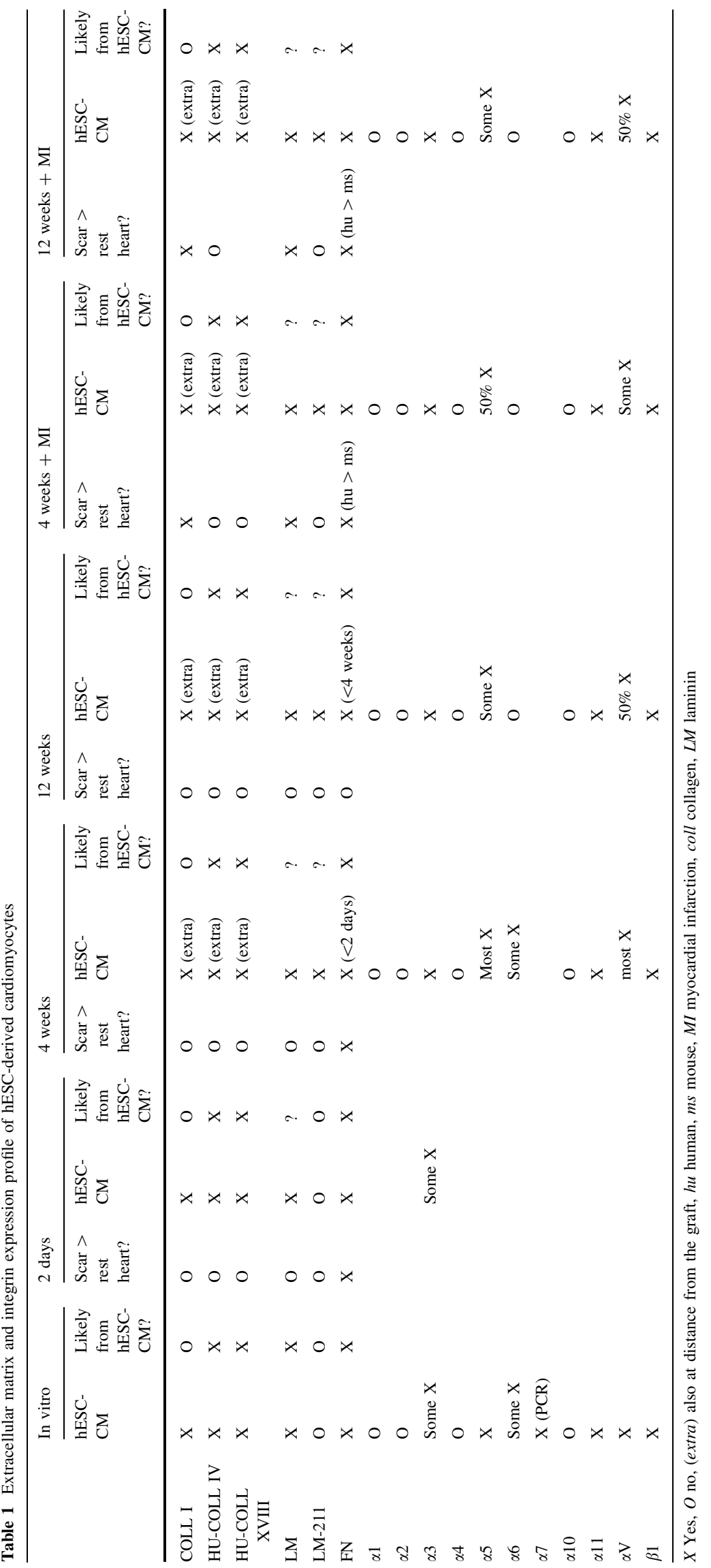



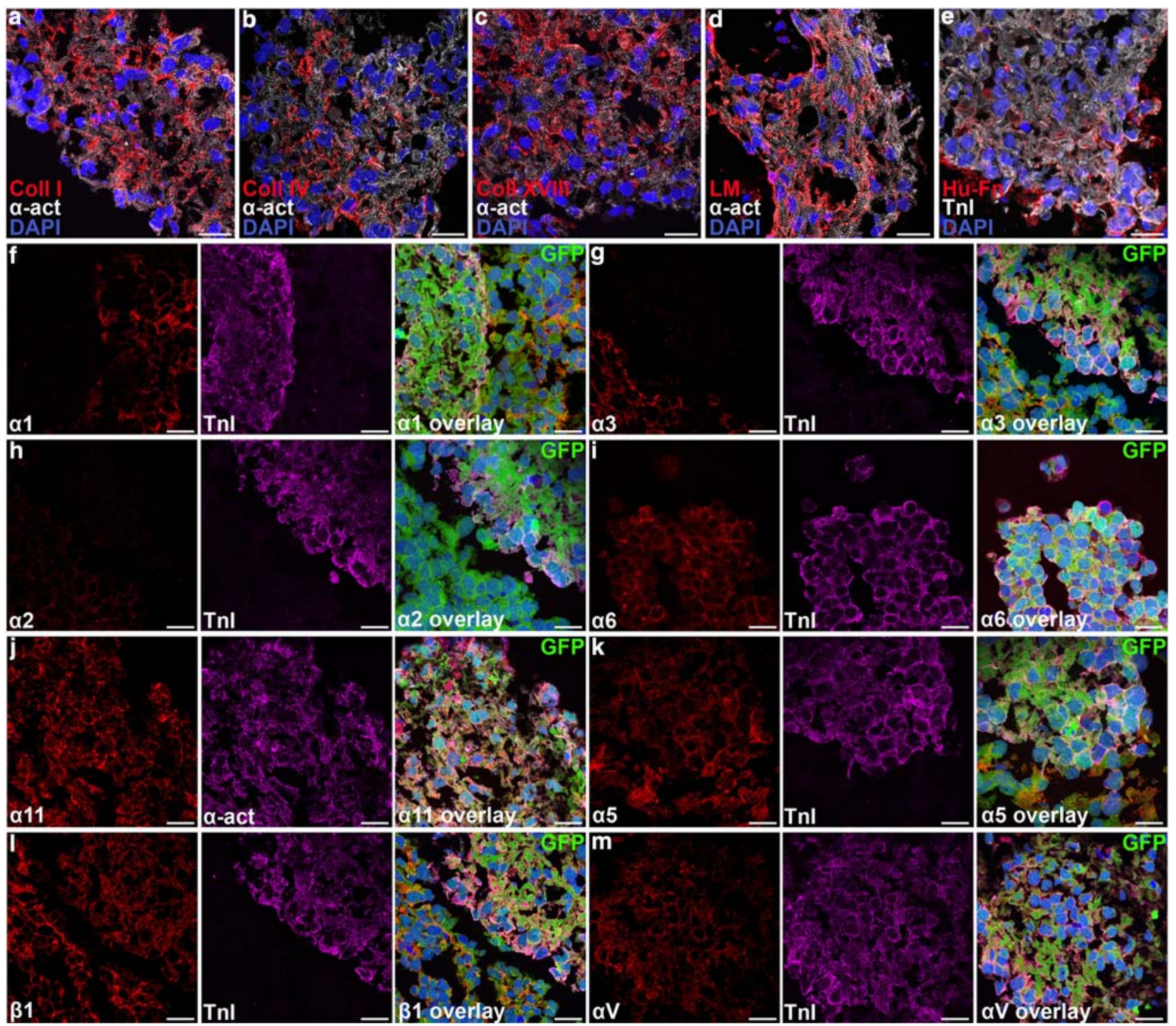

Fig. 1 Extracellular matrix and integrin expression in beating areas from hESCs. a-e hESC-CM from hES3-GFP are surrounded by collagen I, collagen IV, collagen XVIII, laminin and fibronectin (GFP not shown for clarity). $\mathbf{f}-\mathbf{m}$ hESC-CM express collagen receptor

integrin $\alpha 11$, some laminin receptors $\alpha 3$ and $\alpha 6$, fibronectin/ vitronectin receptors integrin $\alpha 5$ and $\alpha \mathrm{V}$, and the common $\beta$-subunit integrin $\beta 1$. TnI and $\alpha$-act cardiomyocyte markers troponin I or $\alpha$-actinin, green GFP, blue DAPI. Scale bars $20 \mu \mathrm{m}$

together, the results show that hESC-CM secrete fibronectin which is downregulated after transplantation in the non-infarcted heart. Secretion of mouse fibronectin, on the other hand, appears to be a response to the cell transplantation but is eventually resolved.

Analysis of the integrin expression of hESC-CM in vivo indicated that these cells bind collagens via integrin $\alpha 11$ at all time-points, just as in vitro (Fig. $3 \mathrm{a}$ and Table 1). Laminin-binding integrin $\alpha 3$ was upregulated in vivo, while $\alpha 6$ was slightly downregulated (Fig. 3c, e and Table 1). Integrins $\alpha 5$ and $\alpha \mathrm{V}$, which bind fibronectin and fibronectin/vitronectin, respectively, were reduced over time (Fig. 3b, $\mathrm{d}$ and Table 1). Integrin $\beta 1$ expression remained high at all time-points (Fig. $3 \mathrm{f}$ and Table 1).

We next investigated whether myocardial infarction triggered a different extracellular matrix response to and by hESC-CM grafts by injecting hESC-CM into acutely infarcted mouse myocardium. At 4 and 12 weeks postoperatively, collagen I was a major matrix component of the infarct area and was extensively present around the hESC-CM grafts, as in grafts in non-infarcted hearts (Fig. 4a). Human collagen IV and XVIII were again secreted by hESC-CM, with collagen XVIII in larger quantities than in non-infarcted hearts (Fig. 4c-f). Laminin 
contributed significantly to the infarct area but laminin-211 to a lesser extent (Fig. 4b, g, h); neither increased in relation to the transplanted hESC-CM. Fibronectin was abundant in the infarct zone; in areas with hESC-CM grafts, this included human fibronectin (Fig. 4i, j). Unlike in the non-infarcted heart, the human fibronectin content was still high even at 12 weeks after transplantation. Integrin expression was similar to that of hESC-CM in non-infarcted hearts.

Since fibrosis was present at early time-points and was not degraded 12 weeks post-grafting, the question arose whether transplanted hESC-CM could survive at all for longer periods. We therefore increased follow-up to 24 weeks and found viable grafts that appeared similar to those at 12 weeks in terms of graft size and GFP-fluorescence. At both time-points, the hESC-CM showed signs of maturation in vivo, including loss of punctuate staining for cytokeratin 8 which was found in intracellular keratin threads and desmosomes in immature hESC-CM in vitro (Fig. 5a, b), as previously reported for human fetal cardiomyocytes [29]. However, EM analysis of the grafted cells 24 weeks after transplantation revealed that the hESC-CM had matured further, evidenced by increased myofibril content and improved sarcomeric organization compared to 12 weeks in vivo maturation (Fig. 5c, d). Paradoxically, a fibrotic layer surrounding the graft still largely separated human from mouse myocardium, preventing desmosome formation between human and mouse cells (Fig. 5e) even though desmosomes between human cardiomyocytes were abundant (Fig. 5d). It was thus likely that the grafts received oxygen and nutrients through infiltrating vessels. We observed previously that some mouse-derived vessels were present in the grafts [10]. Surprisingly, a subset of 12- and 24-week hESC-CM grafts (4 out of 16 hearts) were surrounded by small clusters of GFP-expressing cells which formed a mosaic-like pattern with the native mouse cardiomyocytes (Figs. $5 \mathrm{f}$ and $6 \mathrm{a}$ ). The morphology of these hESC-derived cells was typical of endothelial cells: long flat cells aligning into capillaries (Fig. 6d) with the typical appearance of caveolae and Weibel-palade bodies. The capillaries consisted uniquely of GFP-expressing human endothelial cells but were connected to the mouse vasculature, as evidenced by the presence of mouse leukocytes and erythrocytes in their lumen (Fig. 6b, c), and were associated with an increased vascular density in the area around the grafts.

We next sought to distinguish whether the observed endothelial cells were formed from in vivo differentiation of hESCs or supplementary co-injection of in vitro differentiated hESCs into endothelial cells. We found that some hESC-derived beating areas, the starting material for transplantations, contained tube-like structures that expressed human von Willebrand factor and human
Fig. 2 hESC-CM secrete extracellular matrix and evoke excessive matrix production by host cells after intramyocardial transplantation. a-b Large amounts of collagen I surrounding grafts 2 days and 12 weeks after transplantation. c-d Human collagen IV in the immediate proximity of hESC-CM. e-f Human collagen XVIII in the immediate proximity of hESC-CM. $\mathbf{g}-\mathbf{h}$ Laminin envelops hESC-CM in similar amounts as host cardiomyocytes. $\mathbf{i}-\mathbf{j}$ Laminin-211 is increasingly present around transplanted hESC-CM and eventually in similar amounts as host cardiomyocytes. k-l hESC-CM secrete fibronectin at early time-points after transplantation, but this is reduced over time. Scale bars $20 \mu \mathrm{m}$

PECAM-1 (CD31) (Fig. 6e). Donor-derived neovascularization was thus most likely a result of the supplementary co-injection of hESC-endothelial cells (hESC-EC) with hESC-CM, although there may have been bipotent cardiac progenitors present as many of the cells expressed Isl1 $[6,30]$. In addition, a proportion of the hESC-EC population was still proliferating both in vitro and in vivo (Fig. $6 \mathrm{f}-\mathrm{h}$ ).

To exclude the possibility that undifferentiated hESCs were unintentionally co-transplanted and subsequently contributed to neovascularization, we analyzed hESC ultrastructural characteristics and compared these with grafted cells and beating areas. We found no similarities in the ultra-structure of GFP-cells in beating areas or in grafts at any time-point with undifferentiated hESCs. Unlike differentiated hESCs, undifferentiated hESCs showed strong immunoreactivity with the stem cell marker Tra-1-60 on their apical side and in the endocytotic and biosynthetic systems (Fig. 6i, j). Thus, formation of hESC-derived capillaries was from co-injected hESC-EC, not from undifferentiated hESCs.

\section{Discussion}

This is the first study to date characterizing the fibrotic response after intramyocardial cell transplantation, describing the integrin expression profile of hESC-CM, and documenting neovascularization following co-transplantation of hESC-CM and hESC-EC into the mouse heart. The key findings can be summarized as follows.

1. hESC-CM in beating areas in vitro are embedded in collagen I, IV and XVIII, laminin, and fibronectin, all of which they can bind via appropriate integrins.

2. After transplantation into immunodeficient mouse hearts, hESC-CM continue to secrete extracellular matrix, in particular collagen IV and XVIII and to a lesser extent fibronectin, while host fibroblasts may contribute to encapsulation of the graft by secreting collagen I. The donor cell contribution of fibronectin and collagen XVIII is increased after transplantation into infarcted hearts. 


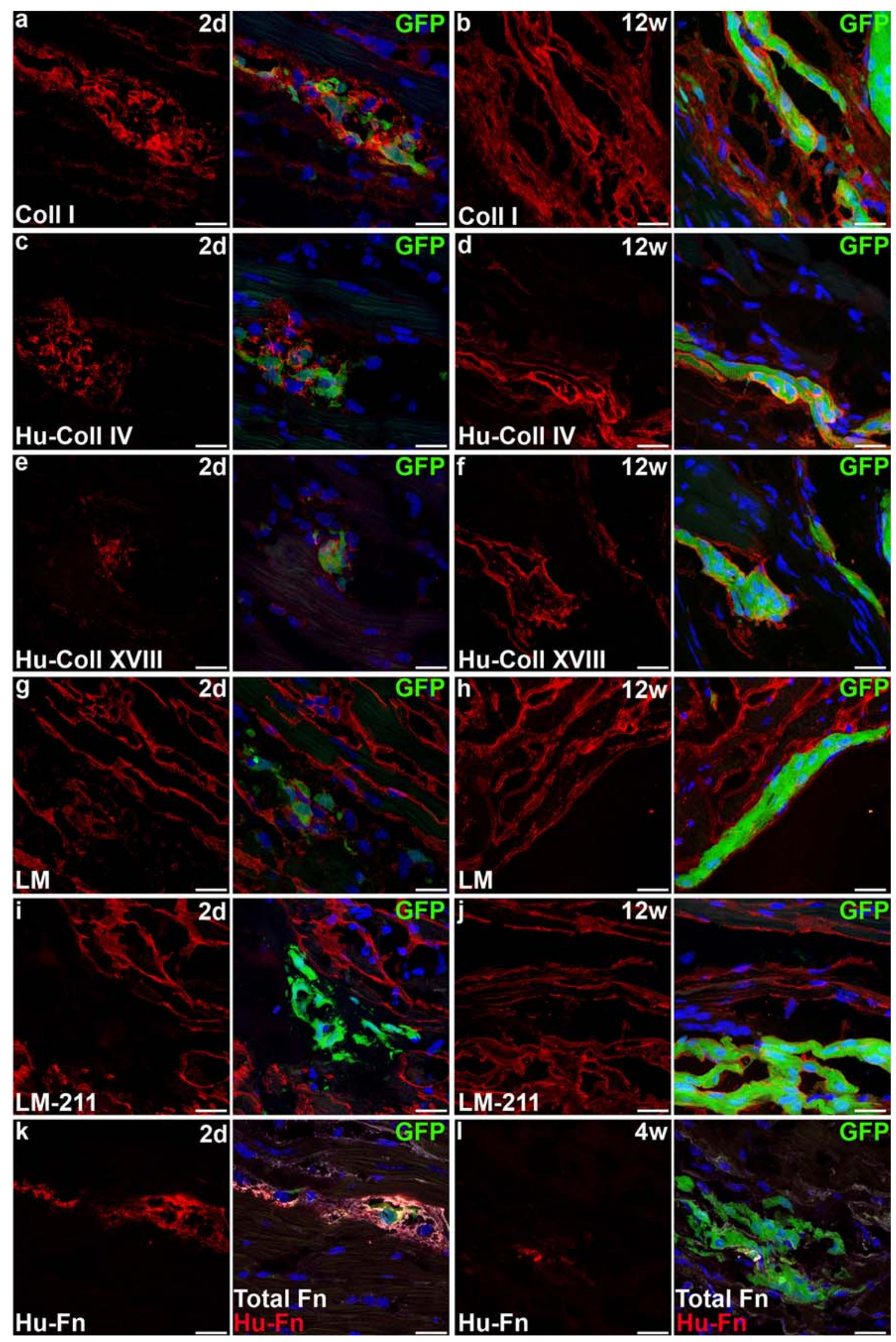



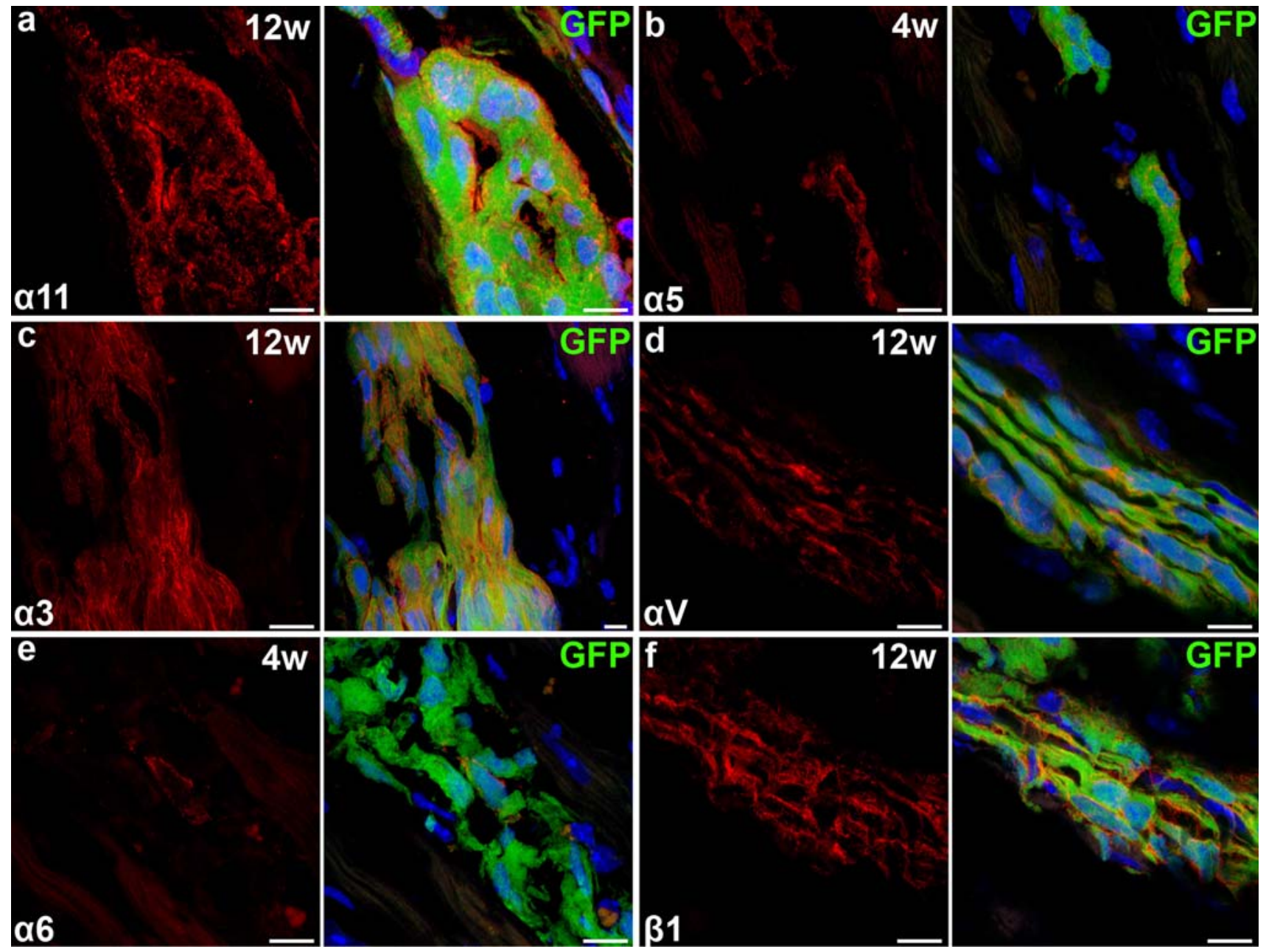

Fig. 3 Integrin expression on hESC-CM after transplantation. a,f Expression of integrin $\alpha 11$ and $\beta 1$ is unchanged. c,e Expression of $\alpha 3$ is upregulated while $\alpha 6$ is slightly downregulated. $\mathbf{b , d} \alpha 5$ and
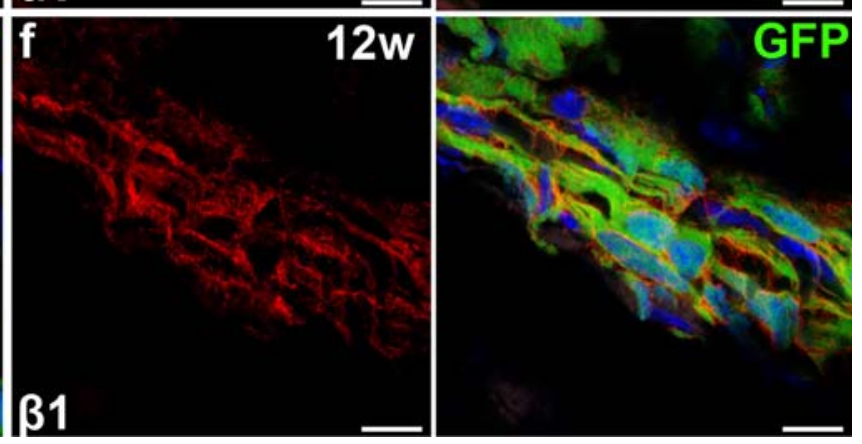

3. Integrin expression on hESC-CM (before and after transplantation) largely matches the matrix type they encounter or secrete in vivo.

4. Co-transplantation of hESC-EC with hESC-CM can result in the formation of functional capillaries which improves blood supply to the grafts.

5. hESC-CM can survive and mature in vivo for at least 24 weeks.

While the extracellular matrix present around hESC-CM beating areas can be secreted by hESC-CM or by other cell types, the human matrix components we identified in grafts of over 4 weeks are most likely produced by cardiomyocytes, since these make up over $90-99 \%$ of the grafts from that time-point onwards [10, 28]. Collagen IV and some fibronectin are secreted by adult cardiomyocytes, although fibronectin is more prominent in the fetal heart [26]. Collagen XVIII is associated with fetal myocardium only, confirming the fetal-like phenotype of hESC-CM [18] even

$\alpha \mathrm{V}$ are decreasingly expressed (see also Table 1). Grafts shown are 4 weeks $(\mathbf{b}, \mathbf{e})$ or 12 weeks $(\mathbf{a}, \mathbf{c}, \mathbf{d}, \mathbf{f})$ after transplantation. Scale bars $10 \mu \mathrm{m}$

though they mature significantly after transplantation. This is also in agreement with our observation that fibronectin secretion by hESC-CM is more pronounced at early timepoints and (like collagen XVIII) after myocardial infarction, when environmental factors upregulate expression of fetal genes [31]. We cannot rule out the possibility that the increased presence of these matrices is caused by slower degradation in the infarcted heart, but this seems unlikely considering the large time differences between the points

Fig. 4 Extracellular matrix secretion from hESC-CM is increased when transplanted into the infarcted heart. a Collagen I forms a large part of the infarct and is present in even larger amounts around the grafted hESC-CM. b Laminin forms part of the infarct and is present in normal quantities around hESC-CM. c-f Human collagen IV (c, overview in d) and human collagen XVIII (e, overview in f) are secreted by hESC-CM and cover a considerable area around the graft. g-h Laminin-211 forms part of the infarct and is present in normal quantities around hESC-CM. $\mathbf{i}-\mathbf{j}$ Fibronectin forms part of the infarct and this is largely due to continuing secretion of human fibronectin by hESC-CM. Scale bars $(\mathbf{a}-\mathbf{c}, \mathbf{e}, \mathbf{g}-\mathbf{j}) 20 \mu \mathrm{m},(\mathbf{d}, \mathbf{f}) 100 \mu \mathrm{m}$ 


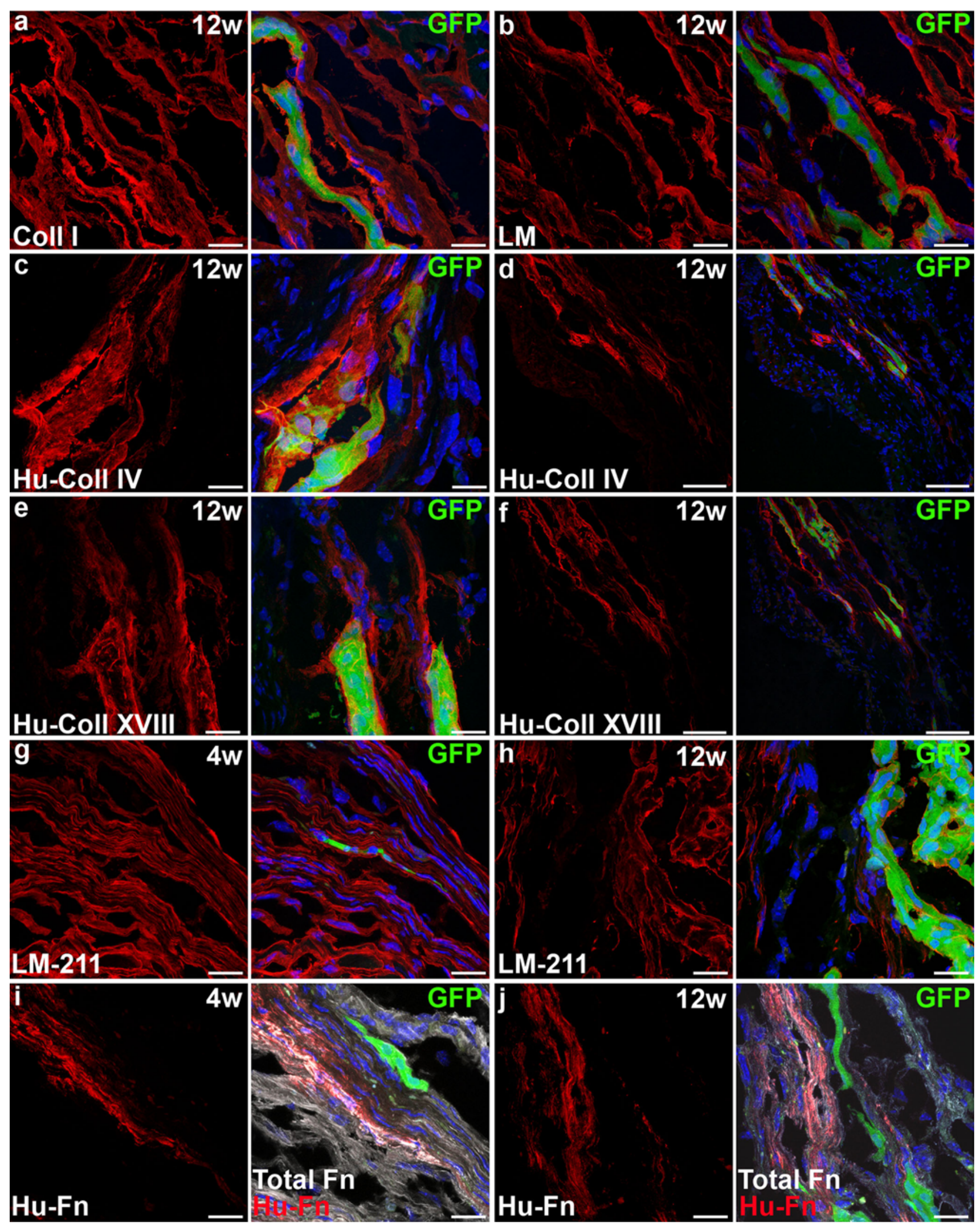


Fig. 5 Survival and continuing maturation of transplanted hESC-CM for at least 24 weeks. a,b Immature hESC-CM in vitro containing poorly organized myofibrils and keratin threads; black dots cytokeratin 8 . c-f hESC-CM grafts; black dots GFP; $d$ desmosome, $n$ nucleus, $m$ myofibrils, $h u$ human, $m s$ mouse, ECM extracellular matrix. c Increased myofibril content and organization and desmosome formation in hESC-CM 12 weeks after transplantation. d Further increased myofibril content and organization and desmosome formation in hESC-CM 24 weeks after transplantation. e Extracellular matrix between donor and host cardiomyocytes 24 weeks after transplantation. f Overview of hESC-CM with flanking hESC-derived endothelial cells $(E C s)$ 24 weeks after transplantation. Scale bars (a-e) $200 \mathrm{~nm}$, (f) $1 \mu \mathrm{m}$
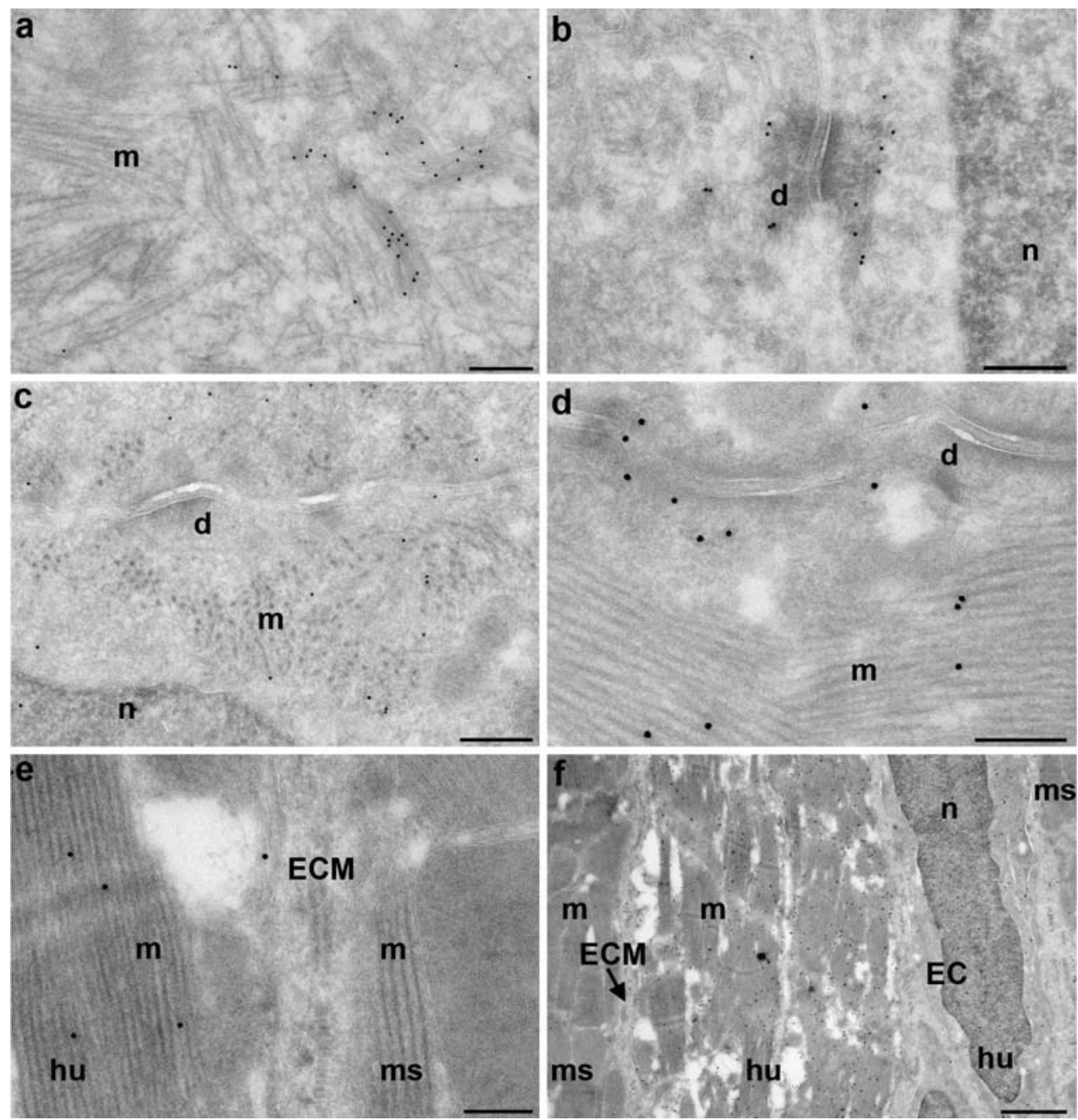

investigated and the shorter turnover time of fibronectin and collagens, especially in myocardial infarction when matrix metalloproteinases (MMPs) are abundantly present [32]. In both non-infarcted and infarcted hearts, transplanted hESC-CM were surrounded by a substantial layer of collagen I that was not cleared over time. Distant from the grafts, the composition of the extracellular matrix in the infarct zone was unaltered by the hESC-CM transplantation compared to previous reports [32-34]. Laminins were not increased in the graft area, and thus the fibrotic tissue separating donor from host cells consists of collagen I and donor-derived collagen IV, collagen XVIII and, in the infarcted heart, fibronectin.

Integrins expressed on HESC-CM mediate binding to each of the matrices described, although we observed some changes in their expression profile after transplantation. The high expression of $\alpha 11$ is consistent with attachment to collagens, and collagen synthesis by hESC-CM may be essential for differentiation and proliferation, as described for mouse ESC-CM and human fetal cardiomyocytes $[35,36]$. Although collagen XVIII is best known as a precursor for endostatin [37], our observations indicate that this collagen likely has a different function in hESC-CM unrelated to inhibition of angiogenesis. Nevertheless, it would be interesting to inhibit collagen XVIII production in hESC-CM and to search for a potential effect on neovascularization after myocardial infarction. Lamininbinding integrins $\alpha 3$ and $\alpha 6$ were expressed at low levels by only a few cells in vitro. After transplantation, however, $\alpha 3$ was markedly upregulated, becoming the principal laminin-binding integrin, possibly together with $\alpha 7$ (which we

Fig. 6 Co-transplanted hESC-ECs form functional vessels in the host myocardium. a Small clusters of GFP-expressing cells scattered through the host myocardium 24 weeks after transplantation, b-d Human endothelial cells forming capillaries in mouse myocardium; black dots GFP, $e$ erythrocyte, $l$ leukocyte, $n$ nucleus, EC endothelial cell, $h u$ human, $m s$ mouse. e Overview of endothelial structures in a beating area from hES3-GFP. f, g Ki-67-positive endothelial cells expressing human PECAM and human von Willebrand Factor. h Ki-67-positive hESC-derived endothelial cells in a graft 12 weeks after transplantation. i,j Undifferentiated hESCs; immunogold labeling for Tra-1-60 at the apical side (i) and intracellular (j); black dots Tra-1-60; $n$ nucleus. Scale bars (a,e) $100 \mu \mathrm{m},(\mathbf{b}, \mathbf{c}) 1 \mu \mathrm{m}$ (d) $500 \mathrm{~nm}(\mathbf{f}, \mathbf{g}) 20 \mu \mathrm{m}(\mathbf{h}, \mathbf{i}) 200 \mathrm{~nm}$ 


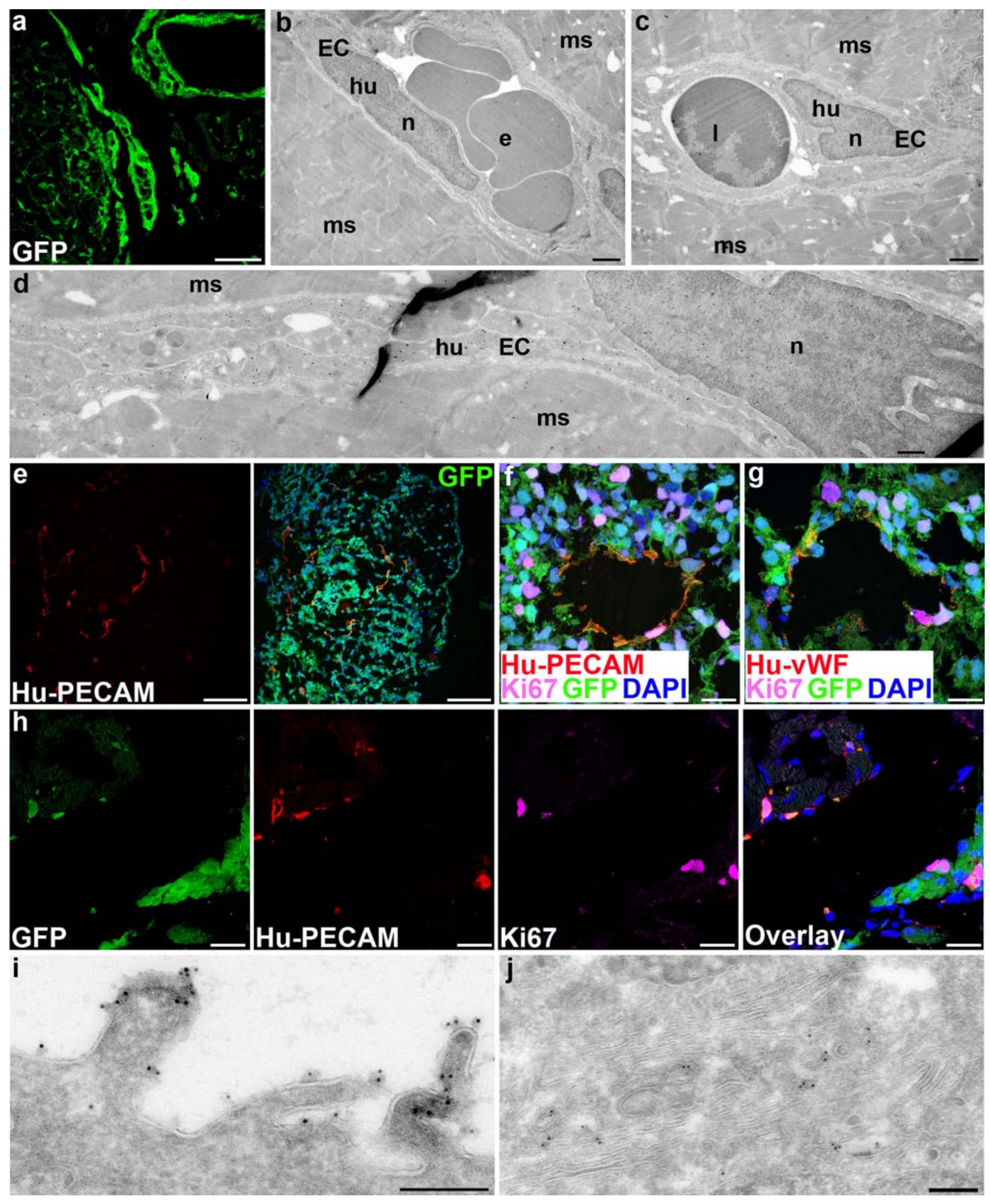

could not quantify because of the lack of an acceptable antibody). One reason for the excessive human fibronectin secretion early after transplantation could be a response to transforming growth factor $\beta$ (TGF $\beta$ ), which is strongly upregulated in the border zone in mice after myocardial infarction and targets, amongst others, the fibronectin gene 
[38]. Fibronectin secretion could also be triggered by suboptimal binding of transplanted hESC-CM to laminin; at early time-points, fibronectin-binding integrins were more prominently expressed than laminin-binding integrins. Since laminin is not secreted in excess, modifying hESC-CM to express more functional laminin-binding and less fibronectin-binding integrins might help to reduce extracellular matrix secretion by hESC-CM and accelerate maturation $[39,40]$, provided their proliferative capacity can be kept intact. Alternatively, co-injecting hESC-CM with a mixture of the extracellular matrix proteins they would otherwise secrete themselves might provide a more gradual habituation of the donor cells and prevent part of their matrix secretion.

Collagen I forms a layer around patches of grafted hESC-CM, presumably a foreign body reaction by mouse fibroblasts. To prevent this in future clinical applications, it is essential that donor and host cells match as closely as possible with regard to immunological, electrophysiological, and mechanical characteristics (such as stiffness), since fibroblasts "sense" discrepancies and respond by producing more extracellular matrix [41]. Other options may include upregulating MMP secretion by hESC-CM, coinjecting MMPs, or co-injecting inhibitors of tissue inhibitors of metalloproteinases (TIMPs). However, these interventions need to be accurately timed and dosed, since an excess of particular MMPs results in adverse remodeling, such as dilatation [32, 42].

Although the excessive deposition of extracellular matrix around intramyocardial grafts needs to be resolved for electrophysiological reasons, it appears that oxygen and nutrient supply to the grafts was established, since survival and ultra-structural maturation were sustained over prolonged periods of 24 weeks. Contributing to this was the co-injection of hESC-EC leading to the formation of functional human capillaries connected to the mouse vasculature. Mouse ESC-EC and hESC-EC differentiation have been described before [43, 44], and mouse ESC-EC increased cardiac function in a mouse model of myocardial infarction [43]. HESC-EC could be selected based on expression of PECAM-1 on their surface. However, coinjection of hESC-CM and hESC-EC has not been investigated to date. With improved selection methods for obtaining pure populations of hESC-CM [45], defined cotransplantation of hESC-CM and hESC-EC has now become a realistic possibility that warrants further exploration for eventual clinical application.

One limitation of our study is the interspecies difference that may prevent functional coupling of donor and host cardiomyocytes, since human cardiomyocytes are unlikely to sustain prolonged periods of relative tachycardia in a mouse heart which beats approximately 500 times per minute. However, the long term survival, maturation, and functional benefits of hESC-CM in this and other rodent in vivo models $[5,10]$ suggests that most other factors are likely to be similar in mouse and human hearts. Importantly, extracellular matrix response after injury in the mouse heart is representative of that seen in the clinical setting, when taking into account that the time course of events is accelerated in mice [34]. Another reason for choosing the mouse as a model system is the availability of NOD-SCID mice, in which the influence of specific immune reactions that might otherwise confound results are reduced. Nevertheless, these experiments eventually need to be repeated isogenically in larger animals, perhaps using induced pluripotent stem (iPS) cells. IPS cells appear to behave much the same as ESCs [46] and have now been derived from species like porcine [47] for which ESCs are not available.

In conclusion, both donor and host cells contribute to excessive extracellular matrix formation after transplantation of hESC-CM into the mouse myocardium, and the donor reaction is more pronounced in the presence of myocardial infarction. Nevertheless, hESC-CM are able to survive and mature after transplantation for prolonged periods of at least 24 weeks, which may be supported by donor-derived capillary formation from co-transplanted hESC-EC. These results form the basis of future developments aiming to reduce the adverse fibrotic reaction that currently complicates cell-based therapies for cardiac disease, and provide additional clues for improving successful engraftment of hESC-CM, and cardiomyocytes in general, by co-transplanting endothelial cells.

Acknowledgments We are grateful to S. van den Brink for cell culture, J. Korving for histology, C. Reijmer for fetal hearts, R. Scriwanek for processing of EM photographs, and N. Sheehy for critical reading of the manuscript. This work was supported by the European Community's Sixth Framework Programme contract ('HeartRepair') [LSHM-CT-2005-018630] (L.v.L, R.P.) and the Dutch Platform for Tissue Engineering (J.M, F.L, L.Z.). L.v.L. received a fellowship from the Interuniversity Cardiology Institute of the Netherlands.

Open Access This article is distributed under the terms of the Creative Commons Attribution Noncommercial License which permits any noncommercial use, distribution, and reproduction in any medium, provided the original author(s) and source are credited.

\section{References}

1. (2007) International Cardiovascular Disease Statistics. American Heart Association

2. Rubart M, Field LJ (2006) Cardiac regeneration: repopulating the heart. Annu Rev Physiol 68:29-49

3. van Laake LW, Hassink R, Doevendans PA, Mummery C (2006) Heart repair and stem cells. J Physiol 577:467-478 
4. Burridge PW, Anderson D, Priddle H, Barbadillo M, Chamberlain S, Allegrucci C, Young LE, Denning C (2007) Improved human embryonic stem cell embryoid body homogeneity and cardiomyocyte differentiation from a novel V-96 plate aggregation system highlights interline variability. Stem Cells 25:929-938

5. Laflamme MA, Chen KY, Naumova AV, Muskheli V, Fugate JA, Dupras SK, Reinecke H, Xu C, Hassanipour M, Police S, O'sullivan C, Collins L, Chen Y, Minami E, Gill EA, Ueno S, Yuan C, Gold J, Murry CE (2007) Cardiomyocytes derived from human embryonic stem cells in pro-survival factors enhance function of infarcted rat hearts. Nat Biotechnol 25:1015-1024

6. Passier R, Oostwaard DW, Snapper J, Kloots J, Hassink RJ, Kuijk E, Roelen B, de la Riviere AB, Mummery C (2005) Increased cardiomyocyte differentiation from human embryonic stem cells in serum-free cultures. Stem Cells 23:772-780

7. Dai W, Field LJ, Rubart M, Reuter S, Hale SL, Zweigerdt R, Graichen RE, Kay GL, Jyrala AJ, Colman A, Davidson BP, Pera M, Kloner RA (2007) Survival and maturation of human embryonic stem cell-derived cardiomyocytes in rat hearts. J Mol Cell Cardiol 43:504-516

8. Kehat I, Khimovich L, Caspi O, Gepstein A, Shofti R, Arbel G, Huber I, Satin J, Itskovitz-Eldor J, Gepstein L (2004) Electromechanical integration of cardiomyocytes derived from human embryonic stem cells. Nat Biotechnol 22:1282-1289

9. Laflamme MA, Gold J, Xu C, Hassanipour M, Rosler E, Police S, Muskheli V, Murry CE (2005) Formation of human myocardium in the rat heart from human embryonic stem cells. Am J Pathol 167:663-671

10. van Laake LW, Passier R, Monshouwer-Kloots J, Verkleij AJ, Lips DJ, Freund C, Den Ouden K, Ward-van Oostwaard D, Korving J, Tertoolen LG, van Echteld CJ, Doevendans PA, Mummery CL (2007) Human embryonic stem cell-derived cardiomyocytes survive and mature in the mouse heart and transiently improve function after myocardial infarction. Stem Cell Res 1:9-24

11. Xue T, Cho HC, Akar FG, Tsang SY, Jones SP, Marban E, Tomaselli GF, Li RA (2005) Functional integration of electrically active cardiac derivatives from genetically engineered human embryonic stem cells with quiescent recipient ventricular cardiomyocytes: insights into the development of cell-based pacemakers. Circulation 111:11-20

12. Ross RS (2004) Molecular and mechanical synergy: cross-talk between integrins and growth factor receptors. Cardiovasc Res 63:381-390

13. Gaudesius G, Miragoli M, Thomas SP, Rohr S (2003) Coupling of cardiac electrical activity over extended distances by fibroblasts of cardiac origin. Circ Res 93:421-428

14. Breithardt G, Borggrefe M, Martinez-Rubio A, Budde T (1989) Pathophysiological mechanisms of ventricular tachyarrhythmias. Eur Heart J 10(Suppl E):9-18

15. Rosenzweig A (2006) Cardiac cell therapy-mixed results from mixed cells. N Engl J Med 355:1274-1277

16. Mannon RB, Kopp JB, Ruiz P, Griffiths R, Bustos M, Platt JL, Klotman PE, Coffman TM (1999) Chronic rejection of mouse kidney allografts. Kidney Int 55:1935-1944

17. Costa M, Dottori M, Ng E, Hawes SM, Sourris K, Jamshidi P, Pera MF, Elefanty AG, Stanley EG (2005) The hESC line Envy expresses high levels of GFP in all differentiated progeny. Nat Methods 2:259-260

18. Mummery C, Ward-van Oostwaard D, Doevendans P, Spijker R, van den Brink S, Hassink R, van der Heyden M, Opthof T, Pera M, de la Riviere AB, Passier R, Tertoolen L (2003) Differentiation of human embryonic stem cells to cardiomyocytes: role of coculture with visceral endoderm-like cells. Circulation 107: 2733-2740
19. Beqqali A, Kloots J, Ward-van Oostwaard D, Mummery C, Passier R (2006) Genome-wide transcriptional profiling of human embryonic stem cells differentiating to cardiomyocytes. Stem Cells 24:1956-1967

20. Moore JC, van Laake LW, Braam SR, Xue T, Tsang SY, Ward D, Passier R, Tertoolen LL, Li RA, Mummery CL (2005) Human embryonic stem cells: genetic manipulation on the way to cardiac cell therapies. Reprod Toxicol 20:377-391

21. van Laake LW, Passier R, Monshouwer-Kloots J, Nederhoff MG, Ward-van Oostwaard D, Field LJ, van Echteld CJ, Doevendans PA, Mummery CL (2007) Monitoring of cell therapy and assessment of cardiac function using magnetic resonance imaging in a mouse model of myocardial infarction. Nat Protoc 2: 2551-2567

22. van Laake LW, van den Driesche DS, Post S, Feijen A, Jansen MA, Driessens MH, Mager JJ, Snijder RJ, Westermann CJ, Doevendans PA, van Echteld CJ, ten Dijke P, Arthur HM, Goumans MJ, Lebrin F, Mummery CL (2006) Endoglin has a crucial role in blood cellmediated vascular repair. Circulation 114:2288-2297

23. Liou W, Geuze HJ, Slot JW (1996) Improving structural integrity of cryosections for immunogold labeling. Histochem Cell Biol 106:41-58

24. Tokuyasu KT (1973) A technique for ultracryotomy of cell suspensions and tissues. J Cell Biol 57:551-565

25. Slot JW, Geuze HJ (1981) Sizing of protein A-colloidal gold probes for immunoelectron microscopy. J Cell Biol 90:533-536

26. Baharvand H, Azarnia M, Parivar K, Ashtiani SK (2005) The effect of extracellular matrix on embryonic stem cell-derived cardiomyocytes. J Mol Cell Cardiol 38:495-503

27. Carvalhaes LS, Gervasio OL, Guatimosim C, Heljasvaara R, Sormunen R, Pihlajaniemi T, Kitten GT (2006) Collagen XVIII/ endostatin is associated with the epithelial-mesenchymal transformation in the atrioventricular valves during cardiac development. Dev Dyn 235:132-142

28. van Laake LW, Passier R, Doevendans PA, Mummery CL (2008) Human embryonic stem cell-derived cardiomyocytes and cardiac repair in rodents. Circ Res 102:1008-1010

29. Kuruc N, Franke WW (1988) Transient coexpression of desmin and cytokeratins 8 and 18 in developing myocardial cells of some vertebrate species. Differentiation 38:177-193

30. Moretti A, Caron L, Nakano A, Lam JT, Bernshausen A, Chen Y, Qyang Y, Bu L, Sasaki M, Martin-Puig S, Sun Y, Evans SM, Laugwitz KL, Chien KR (2006) Multipotent embryonic isl1+ progenitor cells lead to cardiac, smooth muscle, and endothelial cell diversification. Cell 127:1151-1165

31. Thum T, Galuppo P, Wolf C, Fiedler J, Kneitz S, van Laake LW, Doevendans PA, Mummery CL, Borlak J, Haverich A, Gross C, Engelhardt S, Ertl G, Bauersachs J (2007) MicroRNAs in the human heart: a clue to fetal gene reprogramming in heart failure. Circulation 116:258-267

32. Lindsey ML, Mann DL, Entman ML, Spinale FG (2003) Extracellular matrix remodeling following myocardial injury. Ann Med 35:316-326

33. Cleutjens JP, Verluyten MJ, Smiths JF, Daemen MJ (1995) Collagen remodeling after myocardial infarction in the rat heart. Am J Pathol 147:325-338

34. Dobaczewski M, Bujak M, Zymek P, Ren G, Entman ML, Frangogiannis NG (2006) Extracellular matrix remodeling in canine and mouse myocardial infarcts. Cell Tissue Res 324:475-488

35. Hornberger LK, Singhroy S, Cavalle-Garrido T, Tsang W, Keeley F, Rabinovitch M (2000) Synthesis of extracellular matrix and adhesion through beta(1) integrins are critical for fetal ventricular myocyte proliferation. Circ Res 87:508-515

36. Sato H, Takahashi M, Ise H, Yamada A, Hirose S, Tagawa Y, Morimoto H, Izawa A, Ikeda U (2006) Collagen synthesis is required for ascorbic acid-enhanced differentiation of mouse 
embryonic stem cells into cardiomyocytes. Biochem Biophys Res Commun 342:107-112

37. Marneros AG, Olsen BR (2005) Physiological role of collagen XVIII and endostatin. FASEB J 19:716-728

38. Chuva de Sousa Lopes SM, Feijen A, Korving J, Korchynskyi O, Larsson J, Karlsson S, ten Dijke P, Lyons KM, Goldschmeding R, Doevendans P, Mummery CL (2004) Connective tissue growth factor expression and Smad signaling during mouse heart development and myocardial infarction. Dev Dyn 231:542550

39. Cachaco AS, Pereira CS, Pardal RG, Bajanca F, Thorsteinsdottir S (2005) Integrin repertoire on myogenic cells changes during the course of primary myogenesis in the mouse. Dev Dyn 232: 1069-1078

40. Kim H, Yoon CS, Kim H, Rah B (1999) Expression of extracellular matrix components fibronectin and laminin in the human fetal heart. Cell Struct Funct 24:19-26

41. MacKenna D, Summerour SR, Villarreal FJ (2000) Role of mechanical factors in modulating cardiac fibroblast function and extracellular matrix synthesis. Cardiovasc Res 46:257-263

42. van Laake LW, Vainas T, Dammers R, Kitslaar PJ, Hoeks AP, Schurink GW (2005) Systemic dilation diathesis in patients with abdominal aortic aneurysms: a role for matrix metalloproteinase9? Eur J Vasc Endovasc Surg 29:371-377

43. Li Z, Wu JC, Sheikh AY, Kraft D, Cao F, Xie X, Patel M, Gambhir SS, Robbins RC, Cooke JP, Wu JC (2007) Differentiation, survival, and function of embryonic stem cell derived endothelial cells for ischemic heart disease. Circulation 116:I46I54

44. Levenberg S, Golub JS, Amit M, Itskovitz-Eldor J, Langer R (2002) Endothelial cells derived from human embryonic stem cells. Proc Natl Acad Sci USA 99:4391-4396

45. Huber I, Itzhaki I, Caspi O, Arbel G, Tzukerman M, Gepstein A, Habib M, Yankelson L, Kehat I, Gepstein L (2007) Identification and selection of cardiomyocytes during human embryonic stem cell differentiation. FASEB J 21:2551-2563

46. Takahashi K, Tanabe K, Ohnuki M, Narita M, Ichisaka T, Tomoda K, Yamanaka S (2007) Induction of pluripotent stem cells from adult human fibroblasts by defined factors. Cell 131: 861-872

47. Esteban MA, Xu J, Yang J, Peng M, Qin D, Li W, Jiang Z, Chen J, Deng K, Zhong M, Cai J, Lai L, Pei D (2009) Generation of induced pluripotent stem cell lines from Tibetan miniature pig. J Biol Chem 284:17634-17640 